\title{
The Relevance of Egg Shape, Colouration and Day of Lay in Japanese Quails Production
}

\author{
Ajodoh, R.J
}

\begin{abstract}
The study was conducted to determine the effect of egg shape, coloration pattern and the day of lay of Japanese quail on fertility, hatchability and sex of chicks. A total of 100 quails (50 males and 50 females) of 4-5 weeks of age were paired in a ratio of 1:1 in cages. Eight hundred and nineteen (819) eggs collected for the duration of 5 weeks and were sorted into twelve (12) groups on the basis of their shape, colour and day of lay. The eggs were incubated at various batches. The chicks were maintained into their various groups after hatching and reared for 5-6 weeks their sex was determined. It was observed that there was no significant (P>0.05) difference between the observed egg shapes and colour patterns in Japanese quail .However, the result showed that the number of spherical oval eggs were more than the conical oval eggs. The tan coloured eggs were more than the brown eggs while the straw coloured eggs were few in the distribution. There was no significant $(P>0.05)$ difference between the shape, colour, day of lay and batch of incubation on sex of the chicks. The result of the effect of egg shape, colour, day of lay and batch of incubation on fertility showed that there were no significant (P>0.05) influence of egg shape, colour, day of lay and batch of incubation on fertility. Egg shape, colour, day of lay and batch of incubation had no significant $(P>0.05)$ influence on hatchability but the combinations of egg shape, colour and day of layhad a significant $(P<0.05)$ influence on hatchability. The result of both egg shape, colour, day of lay and batch of incubation and their combinations had no significant $(P>0.05)$ influence on embryonic mortality. However, the result revealed that spherical oval shape had less embryonic mortality (10.5\%) compared to conical oval (21.8).the combination of spherical oval day 1 had minimum embryonic mortality of less than 10\% (8.5\%) while conical oval day 1 brown had highest embryonic mortality of 38.9\%.egg shape, colour, day of lay and batch of incubation had no significant $(P>0.05)$ influence on attainment of sexual maturity but the combination of egg shape, colour and day of lay had a significant $(P<0.05)$ influence on attainment of sexual maturity. This implies that the combination of egg shape, colour and day of lay can be used to determine the hatched chicks that would survive to sexual maturity in quails.
\end{abstract}

Keywords: quails, hatchability, colour, egg shape

\section{Introduction}

Animal protein is essential in human nutrition because of its biological significance and the poultry sub-sector is vital to its provision to the Nigerian populace. The poultry industry in Nigeria has hitherto been dominated by rearing of domestic chickens. However, in recent times there have been new entrants into the sector. One of the poultry species slowly gaining prominence is the Japanese quail (Cortunixcoturnix japonica) which is suited for commercial rearing, meat and egg production under intensive management (Egbeyale et al., 2013). Quails have a lower feed requirement compared to the chicken and also require minimal space for rearing (Ijaiya et al., 2013). They thrive well in small cages and can be reared at a cheaper cost within a relative short time (Ojo et al., 2011). Quails require less vaccine per shot because of their resistance to most poultry diseases and they have a high rate of egg production ranging between 200 and 300 eggs during the period of up to 360 days.

Hemid et al. (2010) reported that quails have a short generation interval, high rate of lay and much lower feed and space requirements than the domestic fowl. Quail eggs are very rich in vitamin $\mathrm{D}$, antioxidants which according to Sahin et al. (2008) improve the quality of food from animal origin in terms of colour, oxidative stability, tenderness and storage properties. They have a highly positive effect on people with stress problems, hypertension, digestive disturbance, gastric ulcer, liver problems, bronchitis illness, depression, panic and anxiety illness. The nutritional value of quail eggs is 3-4 times greater than the nutritional value of chicken eggs (Tunsaringkarn et al., 2013). Quail eggs are also known to increase sexual appetite, stimulate brain functions which improve intelligence quotient and generally rejuvenate the body (Onyewuchi et al., 2013). There are also some claims that consumption of quail eggs fortifies the woman's body during pre- and postnatal periods as well as after surgery and radiotherapy (Onyewuchi et al., 2013) Quail meat is tastier than chicken and has less fat content (Igado and Aina, 2010). Generally, products from quail birds are known for their high quality protein, high biological value and low caloric content, making it a choice product for a hypertensive patient (Sahin et al., 2008).

Protein nutritional insecurity is still prominent in most developing countries (including Nigeria). Protein intake has been on a decline due to the ever increasing population (Etim et al., 2008) and this level of animal intake has a direct effect on the health and general well-being of the teeming Nigerian populace (Bamgbose et al., 2002). Chicken meat and egg which have been a major source of animal protein have been unable to meet the demands for protein (Igado and Aina, 2010) .in order to maximize food production and meet the protein requirements in Nigeria, viable options need to be explored and evaluated (Owen et al., 2008).Among such alternatives is the use of species that have a promising economic, health and nutritional benefits of which quails production is one.

Every business plan must be clearly defined and need to answer the question of what to produce, Service or services to render. The major products of any poultry business could be egg, meat or day old chicks and as such commercial poultry companies; small-scale and individual poultry farmers must be explicit in terms of their products. The supply of day old chicks is very paramount to the success of the poultry chain. It becomes very imperative for sex of a chick to be determined at day old so that buyers of day old

Volume 5 Issue 6, June 2016 www.ijsr.net 


\section{International Journal of Science and Research (IJSR) \\ ISSN (Online): 2319-7064 \\ Index Copernicus Value (2013): 6.14 | Impact Factor (2015): 6.391}

chick scan now buy the sex that suit the particular business plan they have that is male chicks for meat production and female chicks for egg production. Unlike chicken that their sex can be separated at day old, up till date, there is no clear method to separate the sex of quail bird at day old. This study therefore was an attempt to relate the shapes, coloration pattern and day of lay of an egg to the sex of the chick.

\section{Materials And Methods:}

\section{Site of the experiment}

The experiment was conducted at the poultry unit of the teaching and research farm, department of animal science Ahmadu Bello University, Zaria. Zaria is located within the northern guinea savannah of Nigeria, latitude $11^{0} 12^{1} \mathrm{~N}$ and longitude $7^{0} 33^{1} \mathrm{E}$, at an altitude of $610 \mathrm{~m}$ above the sea level. The climate is relatively dry, with a mean annual rainfall of $700-1400 \mathrm{~mm}$, occurring between the months of April and September the dry season begins around the middle of October, with dry cold weather that ends in February. This is followed by relatively hot, dry weather from March to sometimes in April, whenthe rain begin. The mean minimum and maximum daily temperature is from about $14^{\circ} \mathrm{c}$ to $24^{\circ} \mathrm{c}$ during the cool season and from about $19^{\circ} \mathrm{c}$ to $36^{\circ} \mathrm{c}$ during the hot season. The relative humidity varies between $19 \%$ and $35 \%$ in dry season and between $63 \%$ and $80 \%$ in the wet season (Akpaet al.2002)

\section{Source and management of experimental birds}

Japanese quail (Coturnixcoturnix japonica) used for the study was purchased from a quail merchant in $\mathrm{PZ}$ Zaria.Experimental Birds and Design: Hundred (100) point of lay, Quails at 5-6weeks (50-males and 50-females) were used for the study. The birds were paired in cages using a mating ratio of 1:1 i.e. one male to one female for the first phase of the experiment. The second phase of the experiment was when the bird started laying. The experimental design was that of a factorial arrangement considering the shape of the egg (grouped into two i.e. spherical oval and conical oval shapes), colourationpattern (grouped into three i.e. Brown, tan and straw colors as the main effect and the day of lay separated into day 1 and day 2 as the interaction making up a $2 * 3 * 2$ factorial arrangement in a randomized completely blocked design. Feed and water were given ad libitum throughout the experimental period. Also standard management practices were strictly observed. Daily record of egg laid were taken indicating parameters such pen number and the weight of the egg ( $g$ ).Total egg collection per day were sorted into the various shapes, colors and the day of lay.Parmanent marker was used to mark the eggs into, their group of shape, color and the day of lay in accordance with the experimental design. The total collections for the period of seven days were incubated for
16-18 day. The hatched chicks with their existing groups established already were housed in their different compartment and raised to maturity until their sex were determined.

\section{Statistical Analysis}

The data collected were imputed and subjected to analysis of variance using the general linear model (GLM) procedure of SAS (2001).However, fertility, hatchability and sex determination data were subjected to chi square analysis.

\section{Results}

\section{Egg shape and colouration pattern}

Table 1 shows the observable shape and colour pattern in Japanese quails. The chi-square analysis showed no significant $(\mathrm{P}>0.05)$ difference between the egg shapes and colour pattern distribution in Japanese quail.However,the frequency distribution showed that the spherical oval shaped eggs in Japanese quail was $6 \%$ higher than those of conical oval shaped eggs. Also in terms of colour distribution, the tan coloured eggs $(53.1 \%$ ) was $7.7 \%$ more in number to brown eggs (45.4\%). The table also showed that the Japanese quail rarely laid straw colour eggs, which was only $1.5 \%$.

Table 1: Observable egg shape and color patterns in Japanese quails

\begin{tabular}{|c|c|c|c|c|}
\hline Traits & Observed & Frequency & $\mathrm{X}_{\text {value }}^{2}$ & Los \\
\hline Shape & 819 & 100 & & \\
\hline Spherical oval & 432 & 53 & 0.021 & Ns \\
\hline Conical oval & 387 & 47 & & \\
\hline Color & 819 & 100 & & \\
\hline Brown & 372 & 45.4 & & \\
\hline Tan & 435 & 53.1 & 0.0411 & Ns \\
\hline Straw & 12 & 1.5 & & \\
\hline
\end{tabular}

\section{Laying Pattern, Egg Size, Fertilityand Hatchability}

Sixty days laying pattern, egg size, fertility, hatchability in Japanese quail is shown in table 2.high level of variability exists in sixty days laying pattern ranging from $7.8 \%$ (in average egg weight) to $94.5 \%$ (in embryonic mortality).the 60 days average pattern of lay in Japanese quail was for period inlay (8.87),number of days inlay/period (3.76),number of period skipped (8.08) and average number of day/skip (1.9).the egg size of Japanese quail in sixty days laying period was :total number of egg laid (1237) .Average egg weight (8.9) .fertility,hatchability,embryonic mortality of Japanese quail egg was :51\%,81\% and $31 \%$ respectively. In Japanese quail $58.1 \%$ of hatched eggs lived to attain sexual maturity, $44.7 \%$ of this number were males and $55.3 \%$ female 


\section{International Journal of Science and Research (IJSR) \\ ISSN (Online): 2319-7064}

Index Copernicus Value (2013): 6.14 | Impact Factor (2015): 6.391

Table 2: Sixty days laying pattern, egg size, fertility, hatchability in Japanese quail

\begin{tabular}{|c|c|c|c|c|c|}
\hline Characteristics & $\mathrm{N}$ & Mean+Se & $\mathrm{CV}$ & Min & Max \\
\hline Pattern of lay & & & & & \\
\hline Period inlay & 38 & $8.87 \pm 0.55$ & 37.66 & 2 & 16 \\
\hline Average number of days & 38 & $3.7 \pm 60.26$ & 42.02 & 1 & 15 \\
\hline Inlay /periods & & & & & \\
\hline Number of period skipped & 38 & $8.08 \pm 0.55$ & 41.60 & 1 & 15 \\
\hline Average number of days per skip & 38 & $1.90 \pm 0.17$ & 54.74 & 1 & 23 \\
\hline Egg size & & & & & \\
\hline Total number of egg laid per hen & 38 & $32.60 \pm 1.97$ & 37.00 & 2 & 52 \\
\hline Egg weight at point of lay(g) & 38 & $8.20 \pm 0.181$ & 3.54 & 6 & 11 \\
\hline Average egg weight (g) & 1237 & $8.90 \pm 0.11$ & 7.80 & 5 & 13 \\
\hline Fertility and hatchability & & & & & \\
\hline Fertility (\%) & 819 & $51 \pm 3.74$ & 37.00 & 15 & 100 \\
\hline Hatchability (\%) & 398 & $81 \pm 3.20$ & 25.00 & 23 & 100 \\
\hline Embryonic mortality (\%) & 398 & $0.31 \pm 6.10$ & 94.50 & 0 & 67 \\
\hline Number of quails at sexual maturity & 335 & $197(58.8 \%)$ & & & \\
\hline Number of male quails at sexual maturity & & $88(44.7 \%)$ & & & \\
\hline Number of female quails at sexual maturity & & $109(55.3 \%)$ & & & \\
\hline
\end{tabular}

\section{Sex Determination of Japanese Quail}

Table 3 shows the determination of sex of Japanese quail chicks using egg shape, colour and day of lay and batch of incubation.Chi-sqare analysis of the distribution of male and female quail chicks showed that these factors had no significant ( $\mathrm{P}>0.05$ ) influence on the sex determination of the chicks. All the same, the spherical oval shaped eggs had $6 \%$ more females than males while the conical oval shaped eggs had $17 \%$ more females than males. The brown colored eggs had $20.76 \%$ more females than male .Therefore; egg shape on its own cannot differentiate the sexes while egg colour could be a promising tool of use. Irrespective of the day of lay, female quail chicks were more than the male chicks. On the account of batch of incubation, batch 5 had $53.84 \%$ more females than males and batch 1 had 5\% more males than females while thepercentage of females was higher than that of males in the rest of the batches (i.e. batch 2, 3 and 4).

Table 3: Distribution of male and female quails according to shape, color, day of lay and batch of incubation

\begin{tabular}{|c|c|c|c|c|c|}
\hline Factor & $\mathrm{N}$ & Male (\%) & female & $\mathrm{X}_{\text {value }}$ & Los \\
\hline Egg shape & 197 & & & & \\
\hline Spherical oval & 115 & 47.00 & 53.00 & 0.572 & $\mathrm{Ns}$ \\
\hline Conical oval & 82 & 41.50 & 58.50 & & \\
\hline Egg color & 197 & & & & \\
\hline Brown & 91 & 50.55 & 49.45 & & \\
\hline Tan & 106 & 39.62 & 60.36 & 2.410 & $\mathrm{Ns}$ \\
\hline Day of lay & 197 & & & & \\
\hline Day 1 & 99 & 40.40 & 59.60 & & \\
\hline Day 2 & 98 & 48.98 & 51.02 & 1.449 & $\mathrm{Ns}$ \\
\hline Batch of incubation & 197 & & & & \\
\hline 1 & 80 & 52.50 & 47.50 & & \\
\hline 2 & 56 & 42.86 & 57.14 & & \\
\hline 3 & 32 & 43.75 & 56.25 & 5.619 & $\mathrm{Ns}$ \\
\hline 4 & 16 & 31.25 & 68.75 & & \\
\hline 5 & 13 & 23.08 & 76.92 & & \\
\hline
\end{tabular}

The distribution male and female quails according to the combinations of egg shape, colour and day of lay are shown in Table 4.the result showed that in all combinations, there was no clear distinction of either of the sexes. However, in using shape and day, conical oval eggs laid on day 1 had $71.43 \%$ of hatched eggs to be female while $28.57 \%$ of them were males .other combinations in this category were near 50:50 distributions. Under shape and colour combinations, conical oval shaped eggs that were tan coloured had $61.20 \%$ of them as females while spherical oval tan coloured eggs had $59.65 \%$ of them as females. Other combinations in this category were near 50:50 sex distributions. In combining shape, day of lay and colour of egg to determine sex of chicks, female chicks were favored by conical oval day 1 brown eggs (70\%) and conical oval day 1 tan eggs $(72.20 \%)$.the male chicks were favored spherical oval day 1 brown eggs (53.80) and conical oval day 2 brown eggs (52.20).

Table 4: Distribution of male and female quails according to combination of egg shape, colour and day of lay

\begin{tabular}{|l|l|l|l|}
\hline Combinations & $\mathrm{N}$ & Male (\%) & Female (\%) \\
\hline Shape and day & & & \\
\hline Spherical oval day 1 & 71 & 45.07 & 54.93 \\
\hline Spherical oval day 2 & 44 & 50.00 & 50.00 \\
\hline Conical oval day 1 & 28 & 28.57 & 71.43 \\
\hline Conical oval day 2 & 54 & 48.15 & 51.85 \\
\hline Colour and day & & & \\
\hline Brown day 1 & 49 & 48.98 & 51.02 \\
\hline Brown day 2 & 50 & 32.00 & 68.00 \\
\hline Tan day 1 & 42 & 52.38 & 47.62 \\
\hline Tan day 2 & 56 & 46.43 & 53.57 \\
\hline Shape and colour & & & \\
\hline Spherical oval brown & 58 & 53.45 & 46.55 \\
\hline Spherical oval tan & 57 & 40.35 & 59.65 \\
\hline Conical oval brown & 33 & 45.45 & 54.55 \\
\hline Conical oval tan & 49 & 38.80 & 61.20 \\
\hline Shape, day and colour & & & \\
\hline Spherical oval day 1 brown & 39 & 53.80 & 46.20 \\
\hline Spherical oval day 1 tan & 32 & 34.40 & 65.60 \\
\hline Spherical oval day 2 brown & 19 & 52.60 & 47.40 \\
\hline Spherical oval day 2 tan & 25 & 48.00 & 52.00 \\
\hline Conical oval day 1 brown & 10 & 30.00 & 70.00 \\
\hline Conical oval day 1 tan & 18 & 27.80 & 72.20 \\
\hline Conical oval day 2 brown & 23 & 52.20 & 47.80 \\
\hline Conical oval day 2 tan & 31 & 45.20 & 54.80 \\
\hline & & \\
\hline
\end{tabular}

\section{Fertility Determination in Quail Eggs}

Table 5 shows the fertility of quail eggs according to shape, colour, and day of lay and batch of incubation. The chisquare analysis showed that there was no significant

\section{Volume 5 Issue 6, June 2016 www.ijsr.net}




\section{International Journal of Science and Research (IJSR) \\ ISSN (Online): 2319-7064 \\ Index Copernicus Value (2013): 6.14 | Impact Factor (2015): 6.391}

( $>>0.05)$ influence of egg shape, colour and batch of incubation on fertility. The two showed 50:50 fertility, tan colour had $49.4 \%$ fertility and brown colour had $49.2 \%$ fertility but the straw colour had $0 \%$ fertility and therefore, this colour was discarded for further analysis. On the basis of batch of incubation, batch 1 showed the highest fertility $(72.1 \%)$ while batch 4 had the lowest $(37.2 \%)$.

Table 5: Fertility of quail eggs according to shapes, colour, and day of lay and batch of incubation

\begin{tabular}{|c|c|c|c|c|}
\hline Factor & $\mathrm{N}$ & Fertility (\%) & $\mathrm{X}_{\text {value }}^{2}$ & Los \\
\hline Egg shape & & & & \\
\hline Spherical oval & 432 & 48.6 & 0.0089 & $\mathrm{Ns}$ \\
\hline Conical oval & 387 & 48.6 & & \\
\hline Egg colour & & & & \\
\hline Brown & 372 & 49.2 & & \\
\hline Tan & 435 & 49.4 & 0.00089 & $\mathrm{~ns}$ \\
\hline Straw & 12 & 0 & & \\
\hline Day of lay & & & & \\
\hline Day 1 & 421 & 46.6 & 0.0097 & $\mathrm{~ns}$ \\
\hline Day 2 & 398 & 50.8 & & \\
\hline Batch of incubation & & & & \\
\hline 1 & 172 & 72.1 & & \\
\hline 2 & 178 & 51.1 & & \\
\hline 3 & 140 & 42.9 & 0.0141 & $\mathrm{~ns}$ \\
\hline 4 & 129 & 37.2 & & \\
\hline 5 & 200 & 37.5 & & \\
\hline
\end{tabular}

The fertility of quail eggs according to the combinations of egg shape, colour and the day of lay is shown in table 6.the chi-square analysis showed no significant $(\mathrm{P}>0.05)$ difference in the egg fertility of the various combinations. All the same, on the basis of shape and day, the best combination was conical oval by day 2 with $52.4 \%$ level of fertility. For shape and colour, more than $50 \%$ level of fertility was produced by conical oval by brown $(54.30 \%)$ and spherical oval by tan $52(52.70 \%)$. shape by day by colour combinations produced the best fertility i.e. Conical oval by day 2 by brown eggs $(61.33 \%)$; followed by spherical oval by day 2 by tan eggs $(55.00 \%)$ and spherical oval by day 1 by tan eggs (50.50).

Table 6: Fertility of quail eggs according to the combinations of egg shape, colour and day of lay

\begin{tabular}{|c|c|c|c|c|}
\hline Combinations & $\mathrm{N}$ & Fertility (\%) & $\mathrm{X}_{\text {value }}^{2}$ & Los \\
\hline Shape and day & & & & \\
\hline Spherical oval day1 & 221 & 47.96 & & \\
\hline Spherical oval day 2 & 211 & 49.30 & 2.1732 & $\mathrm{~ns}$ \\
\hline Conical oval day 1 & 200 & 45.00 & & \\
\hline Conical oval day 2 & 187 & 52.40 & & \\
\hline Shape and colour & & & & \\
\hline Spherical oval brown & 221 & 45.70 & & \\
\hline Spherical oval tan & 207 & 52.70 & & \\
\hline Conical oval brown & 151 & 54.30 & 4.296 & $\mathrm{~ns}$ \\
\hline Conical oval tan & 228 & 46.50 & & \\
\hline Colour and day & & & & \\
\hline Brown day 1 & 187 & 47.06 & & \\
\hline Brown day 2 & 185 & 48.00 & & \\
\hline Tan day 1 & 225 & 51.31 & 1.069 & $\mathrm{~ns}$ \\
\hline Tan day 2 & 210 & 50.95 & & \\
\hline Shape, day and colour & & & & \\
\hline Spherical oval day 1 brown & 111 & 46.80 & & \\
\hline Spherical oval day 1 tan & 107 & 50.50 & & \\
\hline Spherical oval day 2 brown & 110 & 45.00 & & \\
\hline Spherical oval day 2 tan & 100 & 55.00 & 7.873 & $\mathrm{~ns}$ \\
\hline
\end{tabular}

\begin{tabular}{|c|c|c|c|c|}
\hline Conical oval day 1 brown & 76 & 47.40 & & \\
\hline Conical oval day 1 tan & 118 & 45.80 & & \\
\hline Conical oval day 2 brown & 75 & 61.33 & & \\
\hline Conical oval day 2 tan & 110 & 47.30 & & \\
\hline
\end{tabular}

\section{Hatchability determination in quail eggs}

Table 7 presents the hatchability of quail eggs according to egg shape, colour, day of lay and batch of incubation .chisquare analysis none of the factors can significantly $(\mathrm{P}>0.05)$ could be used to determine hatchability .However, the hatchability distributions along the factors are high (78.2 to $93.8 \%$ ) and only moderate for batch 5 (56.0\%).the hatchability distribution shoed that the spherical oval eggs had $(11.3 \%)$ better hatchability than the conical oval eggs. The brown coloured eggs (1.4\%) and day 2 laid eggs $(6.0 \%)$ had slightly better hatchability than the tan eggs and the day 1 laid eggs respectively.in terms of batch of incubation, the best hatchability was in batch $4(93.8 \%)$ while the lowest was in batch $5(56.0 \%)$.

Table 7: Hatchability of quail eggs according egg shape, colour, and day of lay and batch of incubation

\begin{tabular}{|c|c|c|c|c|}
\hline Factor & $\mathrm{N}$ & Hatchability (\%) & $\mathrm{X}_{\text {value }}^{2}$ & Los \\
\hline Egg shape & & & & \\
\hline Spherical oval & 210 & 89.50 & 0.00092 & $\mathrm{Ns}$ \\
\hline Conical oval & 188 & 78.20 & & \\
\hline Egg colour & & & & \\
\hline Brown & 183 & 84.20 & 0.0004041 & $\mathrm{~ns}$ \\
\hline Tan & 215 & 85.60 & & \\
\hline Day of lay & & & & \\
\hline Day 1 & 196 & 81.10 & 0.0269 & $\mathrm{~ns}$ \\
\hline Day 2 & 202 & 87.10 & & \\
\hline Batch of incubation & & & & \\
\hline 1 & 124 & 89.50 & & \\
\hline 2 & 91 & 89.00 & & \\
\hline 3 & 60 & 90.00 & 0.00788 & $\mathrm{~ns}$ \\
\hline 4 & 48 & 93.80 & & \\
\hline 5 & 45 & 56.00 & & \\
\hline
\end{tabular}

The hatchability of quail eggs according to combinations of egg shape, colour and day of lay is shown in Table 8.the chisquare analysis showed a highly significant $(\mathrm{P}<0.05)$ effect of the various combinations on hatchability All combinations gave high hatchability .Good hatchability was between (61-68) and high hatchability was (7492).However, the combination that gave the best hatchability was spherical oval day1 brown eggs $(92.0 \%)$ while the conical oval day 1 brown eggs $(61.15 \%)$ gave the lowest.

\section{Volume 5 Issue 6, June 2016 www.ijsr.net}




\section{International Journal of Science and Research (IJSR) ISSN (Online): 2319-7064 \\ Index Copernicus Value (2013): 6.14 | Impact Factor (2015): 6.391}

Table 8: Hatchability of quail eggs according to the combination of egg shape, colour and day of lay

\begin{tabular}{|c|c|c|c|c|}
\hline Combinations & $\mathrm{N}$ & Hatchability (\%) & $\mathrm{X}_{\text {value }}^{2}$ & Los \\
\hline \multicolumn{5}{|l|}{ Shape and day } \\
\hline Spherical oval day 1 & 106 & 91.50 & & \\
\hline Spherical oval day 2 & 104 & 87.50 & 21.443 & $* *$ \\
\hline Conical oval day 1 & 90 & 68.90 & & \\
\hline Conical oval day 2 & 98 & 86.70 & & \\
\hline \multicolumn{5}{|l|}{ Shape and colour } \\
\hline Spherical oval brown & 101 & 90.00 & & \\
\hline Spherical oval tan & 109 & 89.00 & 9.824 & *** \\
\hline Conical oval brown & 82 & 76.80 & & \\
\hline Conical oval tan & 106 & 79.20 & & \\
\hline \multicolumn{5}{|l|}{ Colour and day } \\
\hline Brown day 1 & 88 & 79.55 & & \\
\hline Brown day 2 & 95 & 93.68 & 3.079 & ns \\
\hline Tan day1 & 108 & 77.78 & & \\
\hline Tan day 2 & 107 & 85.98 & & \\
\hline \multicolumn{5}{|l|}{ Shape ,day and colour } \\
\hline Spherical oval day1 brown & 52 & 92.00 & & \\
\hline Spherical oval day 1 tan & 54 & 90.70 & & \\
\hline Spherical oval day 2 brown & 49 & 87.80 & 24.603 & *** \\
\hline Spherical oval day 2 tan & 55 & 87.30 & & \\
\hline Conical oval day 1 brown & 36 & 61.10 & & \\
\hline Conical oval day 1 tan & 54 & 74.00 & & \\
\hline Conical oval day 2 brown & 46 & 89.00 & & \\
\hline Conical oval day $2 \tan$ & 50 & 84.60 & & \\
\hline
\end{tabular}

\section{Embryonic mortality determination of quail eggs}

Table 9 shows the embryonic mortality of quail eggs according to shape, colour, day of lay and batch of incubation. The chi-square showed a non-significant $(P>0.05)$ effect of egg shape, colour, day of lay and batch of incubation on embryonic mortality. The distribution showed that spherical oval eggs had less embryonic mortality $(10.5 \%)$ while conical oval eggs had $(21.8 \%)$.the brown and tan coloured eggs had equal embryonic mortality (15.8\%).Day 1 eggs had less embryonic mortality (11.2\%) compared to day 2 eggs that had (20.3\%).embryonic mortality was minimal with respect to the batch of hatch $(6.3$ to $10.9 \%$ ) except for batch 5 where it was highest (44\%).

Table 9: Embryonic mortality of quail eggs according to egg shape, colour, day of lay and batch of incubation

\begin{tabular}{|c|c|c|c|c|}
\hline Factor & $\mathrm{N}$ & $\mathrm{EM}(\%)$ & $\mathrm{X}_{\text {value }}^{2}$ & Los \\
\hline Shape of egg & & & & \\
\hline Spherical oval & 210 & 10.50 & 0.000175 & $\mathrm{Ns}$ \\
\hline Conical oval & 188 & 21.80 & & \\
\hline Egg colour & & & & \\
\hline Brown & 183 & 15.80 & 0.000026 & $\mathrm{Ns}$ \\
\hline Tan & 215 & 15.80 & & \\
\hline Day of lay & & & & \\
\hline Day 1 & 196 & 11.20 & 0.00018 & $\mathrm{Ns}$ \\
\hline Day 2 & 202 & 20.30 & & \\
\hline Batch of incubation & & & & \\
\hline 1 & 124 & 8.90 & & \\
\hline 2 & 91 & 10.90 & & \\
\hline 3 & 60 & 10.00 & 0.032 & $\mathrm{Ns}$ \\
\hline 4 & 48 & 6.30 & & \\
\hline 5 & 76 & 4.40 & & \\
\hline
\end{tabular}

EM (embryonic mortality)

Table 10 shows the embryonic mortality of quail eggs according to combinations of egg shape, colour and day of lay the chi-square analysis showed a no significant $(\mathrm{P}>0.05)$ effect .minimal embryonic mortality of less than $10 \%$ was found in the spherical oval day $1(8.5 \%)$ spherical oval brown $(9.9 \%)$, spherical oval day1 brown $(7.7 \%)$.moderate embryonic mortality $(10.15 \%)$ were observed in (conical oval day 2 brown ,spherical oval day $2 \tan$,spherical oval day 2 brown, spherical oval tan ,conical oval day 2 and spherical oval day 2) and embryonic mortality (>15\% to $38.9 \%$ ) were observed in various combinations (conical oval day 1 ,conical oval brown ,conical oval tan ,conical oval day 1 brown, conical oval day 1 tan and conical oval day 2 tan.

Table 10: Embryonic mortality of quail egg according to combinations of egg shape, colour and day of lay

\begin{tabular}{|c|c|c|c|c|}
\hline Combinations & N & $\begin{array}{c}\text { Embryonic } \\
\text { mortality } \\
(\%)\end{array}$ & $X_{\text {value }}^{2}$ & Los \\
\hline Shape and day & & & & \\
\hline Spherical oval day 1 & 106 & 8.50 & & \\
\hline Spherical oval day 2 & 104 & 12.50 & 0.043 & $\mathrm{~ns}$ \\
\hline Conical oval day 1 & 90 & 31.10 & & \\
\hline Conical oval day 2 & 98 & 13.30 & & \\
\hline Shape and colour & & & & \\
\hline Spherical oval brown & 101 & 9.90 & & \\
\hline Spherical oval tan & 109 & 11.00 & & \\
\hline Conical oval brown & 82 & 23.20 & 0.0071 & $\mathrm{~ns}$ \\
\hline Conical oval tan & 106 & 20.80 & & \\
\hline Colour and day & & & & \\
\hline Brown day 1 & 88 & 20.45 & & \\
\hline Brown day 2 & 95 & 20.00 & & \\
\hline Tan day 1 & 108 & 10.20 & 0.00018 & $\mathrm{~ns}$ \\
\hline Tan day 2 & 107 & 14.02 & & \\
\hline Shape, day and colour & & & & \\
\hline Spherical oval day 1 brown & 52 & 7.70 & & \\
\hline Spherical oval day 1 tan & 54 & 9.30 & & \\
\hline Spherical oval day 2 brown & 49 & 12.20 & & \\
\hline Spherical oval day 2 tan & 55 & 12.70 & 6.449 & $\mathrm{~ns}$ \\
\hline Conical oval day1 brown & 36 & 38.90 & & \\
\hline Conical oval day 1 tan & 54 & 25.90 & & \\
\hline Conical oval day 2 brown & 46 & 10.90 & & \\
\hline Conical oval day 2 tan & 52 & 15.40 & & \\
\hline
\end{tabular}

\section{Attainment of sexual maturity in quails}

The distribution of the number of quails birds that attained sexual maturity in accordance with egg shape ,colour ,day of lay and batch of incubation is shown table 11.chi-square analysis of the distribution of attainment of sexual maturity in bird showed no significant $(\mathrm{P}>0.05)$ influence of egg shape ,colour, day of lay and batch of incubation on it.However,the percentage distribution of sexual maturity of quail chicks hatched from spherical oval eggs showed 5.4\% superiority over conical oval eggs in attainment. Quails hatched brown eggs were 0.5 superior to those of from tan eggs while chicks from eggs laid on day 1 were $6.6 \%$ superior to those on day 2.attainment of sexual maturity decreased from batch $1(70.8 \%)$ to batch $5(30.5 \%)$ at an increasing rate of $9.97 \%$.

\section{Volume 5 Issue 6, June 2016 www.ijsr.net}




\section{International Journal of Science and Research (IJSR) \\ ISSN (Online): 2319-7064}

Index Copernicus Value (2013): 6.14 | Impact Factor (2015): 6.391

Table 11: Distribution of attainment of sexual maturity in quails by egg shape, colour, and day of lay and batch of incubation

\begin{tabular}{|c|c|c|c|c|}
\hline Factor & $\mathrm{N}$ & $\begin{array}{c}\text { Attainment of sexual } \\
\text { maturity }\end{array}$ & $\mathrm{X}_{\text {value }}^{2}$ & Los \\
\hline Egg shape & & & & \\
\hline Spherical oval & 188 & $115(61.2)$ & 0.0102 & $\mathrm{Ns}$ \\
\hline Conical oval & 147 & $82(55.8)$ & & \\
\hline Egg colour & & & & \\
\hline Brown & 154 & $91(59.1)$ & & \\
\hline Tan & 181 & $106(58.6)$ & 0.0033 & $\mathrm{Ns}$ \\
\hline Day of lay & & & & \\
\hline Day 1 & 159 & $99(62.3)$ & & \\
\hline Day 2 & 176 & $98(55.7)$ & 0.0051 & $\mathrm{Ns}$ \\
\hline Batch of incubation & & & & \\
\hline 1 & 113 & $80(70.8)$ & & \\
\hline 2 & 81 & $56(69.1)$ & & \\
\hline 3 & 54 & $32(59.3)$ & 0.0764 & $\mathrm{Ns}$ \\
\hline 4 & 45 & $16(35.6)$ & & \\
\hline 5 & 42 & $13(30.9)$ & & \\
\hline
\end{tabular}

Table 12 shows the distribution of attainment of sexual maturity in quails according to combinations of egg shape, colour and day of lay. The chi-square analysis showed a significant $(\mathrm{P}<0.05)$ effect of combinations of shape, colour and day of lay on attainment of sexual maturity of quails this means that the combination of shape of eggs and the day of lay can be used to determine the hatched chicks that would survive to sexual maturity in quails. Considering shape and day of combinations, spherical oval day 1 produced the highest number of chicks that survived to attain sexual maturity (73.2\%) followed by conical oval day $2(63.5 \%)$.For shape and colour considerations, the best result was for spherical oval brown egg chicks (63.7\%). The three -way combinations showed that the best result for attainment of sexual maturity was for chicks that hatched from spherical oval day 1 tan eggs $(81.3 \%)$; followed by conical oval day 2 tan eggs (70.5\%) and spherical oval day 1 tan eggs $(65.3 \%)$

Table 12: Distribution of attainment of sexual maturity in quails according to combination of egg shape, colour and day of lay

\begin{tabular}{|c|c|c|c|c|}
\hline Combinations & $\mathrm{N}$ & ASM & $\mathrm{X}_{\text {value }}^{2}$ & Los \\
\hline Shape and day & & & & \\
\hline Spherical oval day 1 & 97 & $71(73.2)$ & & \\
\hline Spherical oval day 2 & 91 & $44948.4)$ & 15.319 & $* *$ \\
\hline Conical oval day 1 & 62 & $28(45.2)$ & & \\
\hline Conical oval day 2 & 85 & $54(63.5)$ & & \\
\hline Shape and colour & & & & \\
\hline Spherical oval brown & 91 & $58(63.7)$ & & \\
\hline Spherical oval tan & 97 & $57(58.8)$ & 2.008 & $\mathrm{~ns}$ \\
\hline Conical oval brown & 63 & $33(52.4)$ & & \\
\hline Conical oval tan & 84 & $49(58.3)$ & & \\
\hline Colour and day & & & & \\
\hline Brown day 1 & 70 & $49(70.0)$ & & \\
\hline Brown day 2 & 84 & $50(59.52)$ & 0.0004 & $\mathrm{~ns}$ \\
\hline Tan day 1 & 89 & $42(47.19)$ & & \\
\hline Tan day 2 & 92 & $56(60.87)$ & & \\
\hline Shape, colour and day & & & & \\
\hline Spherical oval day 1 brown & 48 & $39(81.3)$ & & \\
\hline Spherical oval day1 tan & 49 & $32(65.3)$ & & \\
\hline Spherical oval day 2 brown & 43 & $19(44.2)$ & & \\
\hline Spherical oval day 2 tan & 48 & $25(52.1)$ & 22.832 & $* *$ \\
\hline Conical oval day 1 brown & 22 & $10(45)$ & & \\
\hline
\end{tabular}

\begin{tabular}{|c|c|c|c|c|}
\hline Conical oval day 1 tan & 40 & $18(45)$ & & \\
\hline Conical oval day 2 brown & 41 & $23(56.1)$ & & \\
\hline Conical oval day 2 tan & 44 & $31(70.5)$ & & \\
\hline
\end{tabular}

ASM (attainment of sexual maturity)

\section{Discussion}

Egg shape and colouration pattern in Japanese quails The identified egg shapes (i.e. conical oval and spherical oval shapes) are fairly in agreement with a documentary from Alberta government 2006 and 2010 which states that "egg shape is usually fairly consistent within a given species, but eggs from different species can vary in roundness and include spherical, sub spherical and elongate shapes with the ends either equal or asymmetric".

Spherical and conical oval shapes are also in agreement with the Wikipedia report in March, 2005 which says that "egg shape has oval shape with small differences among species .The shape of an egg has considered as an important factor to characterize species of birds. The egg of pheasant, chukar, quail and quinea fowl showed circular oval conical shape with blunt and pointed ends.

Coturnix eggs according to Poole, (1965) are characterized by a variety of colour patterns, ranging from dark brown, blue and white to buff each heavily mottled with black brown and blue. Thesis not far from the identified brown, tan and straw colours. The little variation may be due to some environmental and physiological factors that affects egg colouration and also the scale of measurement.

\section{Effect of egg shape and colouration pattern on fertility,} hatchability and embryonic mortality

There are many contradicting report in literature as regards to the effect of egg shape and colouration on fertility, hatchability and embryonic mortality. The chi-square analysis of the combination of egg shape, colour and day of lay showed a highly significant $(\mathrm{p}<0.01)$ effect on hatchability. This is in support of the Narashin and Roanov (2002) who reported that; "egg shape and colour are highly heritable and affect the number of eggs that hatch.

The spherical oval shaped eggs had (11.3\%) better hatchability than the conical oval eggs. This is in disagreement with Joseph et al (2010) who reported that egg closest to the ovoid shape hatched best and that excessively long, thin or completely round eggs do not hatch.

According to Moreno et al (2006),"dark coloured eggs had higher fertility rate and also hatched at higher rate that did light coloured eggs". This statement is fairly in agreement with the result though not significant $(\mathrm{P}>0.05)$ the brown and tan colour eggs showed 50:50 fertility but on hatchability, the brown coloured eggs had slightly better hatchability than the tan coloured eggs.

Effect of egg shape and colouration on sex determination The result of the effect of egg shape on sex showed that egg shape had no significant influence $(\mathrm{P}>0.05)$ on sex. All the same, the spherical oval eggs had $6 \%$ more females than male while the conical oval shaped eggs had $17 \%$ females than the males. This is fairly in agreement with Bramwell et 


\section{International Journal of Science and Research (IJSR) \\ ISSN (Online): 2319-7064}

Index Copernicus Value (2013): 6.14 | Impact Factor (2015): 6.391

al, (2003) who reported that different sexes require different shaped egg for optimum growth within the shell and that the hen's body knows which sex the chick would be .football shaped eggs house boy chicks and more oval or round shaped eggs will house girl chicks. The result disagreed with Don et al, (20011), who stated that the shape of an egg somehow determines the sex of chick that will hatch. According to this school of thought, pointed or elongated eggs will hatch cockerels and round eggs pullets.

According to the literatures, there is no clear report on the relationship between the colour of eggs and the chicks sex or the combinations of shape and colour on sex but according to this study, the shape on its own cannot differentiate the sexes while colour could be a promising tool of use. The result showed that the brown coloured eggs had $1.1 \%$ more males than the females while the tan coloured eggs had $20.76 \%$ more females than males.in combining shape, colour and day of lay, the result showed that in all combinations, there was no clear distinction of either of the sexes. However combinations of shape and day showed that conical oval eggs laid on day 1 , had $71.43 \%$ of hatched eggs to be female while $28.57 \%$ of them were males. Other combinations showed almost 50:50 sex distribution.

\section{Conclusion}

The egg shape, colour and day of lay is significant in Japanese quail breeding practices in the Northern guinea savannah zone of Nigeria. Quail egg shape on its own was poor in sex determining of chicks. However, egg colour especially tan colour had good promise in sex determination of chicks overwhelmingly, the combination egg shape and day of lay or egg colour and day of lay have good promise for sex determination in Japanese quails. Also a combination of the shape of an egg and the day of lay can be used to successfully determine the survivability of hatched quail chicks to sexual maturity.

\section{References}

[1] Adeogun,I.O. and Adeoye, A.A.(2004).Heritability and phenotypic correlation of growth performance traits in Japanese quail. Livestock Research for Rural Development, 16:12. gBramwell,R.K.(2003) .Sexing chicks in the backyard flock. Poultry site; vol 5, no 3.

[2] Bamgbose, A.M., Morenikeji, A., Olayemi, W.A., Oso, A.O., Ojo, O.T. (2002): Performance of weaner rabbits fed supplemented Tridaxprocumbens diets. Proceedings of 7th Annual Conference of Animal Science Association of Nigeria (ASAN), Abeokuta, Nigeria, pp. 69-70

[3] Egbeyale, L.T., Fatoki, H.O., Adeyemi, O.A. (2013): Effect of egg weight and oviposition time on hatchability and post hatch performance of japanese quail (Coturnixcoturnix japonica). Nigerian Journal of Animal Production 40:102-110.

[4] Igado, O.O., Aina, O.O. (2010): Some aspects of the neurometrics and oculometrics of the japanese quail (Coturnixcoturnix japonica) in Nigeria. Journal of Morphological Science 27(3-4):133-135.

[5] Ojo, V., Ayorinde, K.L., Fatoki, H.O. (2011): Relationship between body weight and some egg production traits in the Japanese quail. Nigerian Institute of Social and Economic Research, 11(1):89-94.

[6] Onyewuchi, U.U., Offor, I.R., Okoli, C.F. (2013): Profitability of quail bird and egg production in Imo State, Nigeria. Journal of Agriculture, Food and Environment 9(1):40-44.

[7] Sahin, N., Akdemir, F., Orhan, C., Kucuk, O., Hayirli, A., Sahin, K. (2008): Lycopene-enriched quail egg as functional food for humans. Food Research International 41:295-300.

[8] Tunsaringkarn, T., Tungjaroenchai, W., Siriwong, W. (2013): Nutrient benefits of Quail (Coturnixcoturnix japonica) eggs. International Journal of Scientific and Research publications 3(5):1-8.

[9] Joseph, M.M., 2006.How to maintain hatching egg quality by egg selection; Commercial chicken meat and egg production ; (5th edition).

[10] Narushin,V.G and M.N. Romanov.(2002). Egg physical characteristics and hatchability. World kpoultB.Sci.J. 58:297-303.

[11] S.A.S. (2001).Statistical Analysis institute user guide. North Carolina, U.S.A

[12] Scanford,J.A., (1957) .A progress report of Coturnix quail investigation in Missouri.Proi.NorthAM.Wildlife conf..22. pp.316-359.

[13] Tunsaringkarn, T., Tungjaroenchai, W., Siriwong, W. (2013): Nutrient benefits of Quail (Coturnixcoturnix japonica) eggs. International Journal of Scientific and Research publications 3(5):1-8.

[14] Hemid, A.F.A., Abd El-Gawad, A.H., El-Wardany, I., El-Daly, E.F., Abd El-Azeem, N.A. (2010): Alleviating effects of some environmental stress factors on productive performance in Japanese quail laying performance. World Journal of Agricultural Sciences 6(5):517-524. 